ARTICLE

https://doi.org/10.1038/s41467-019-12627-2

\title{
Utilizing solar energy to improve the oxygen evolution reaction kinetics in zinc-air battery
}

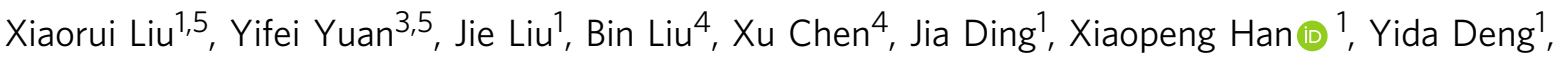 \\ Cheng Zhong (iD ${ }^{1,2 \star} \&$ Wenbin $\mathrm{Hu}^{1,2 \star}$
}

Directly harvesting solar energy for battery charging represents an ultimate solution toward low-cost, green, efficient and sustainable electrochemical energy storage. Here, we design a sunlight promotion strategy into rechargeable zinc-air battery with significantly reduced charging potential below the theoretical cell voltage of zinc-air batteries. The sunlightpromoted zinc-air battery using $\mathrm{BiVO}_{4}$ or $\alpha-\mathrm{Fe}_{2} \mathrm{O}_{3}$ air photoelectrode achieves a record-low charge potential of $\sim 1.20$ and $\sim 1.43 \mathrm{~V}$, respectively, under illumination, which is lowered by $\sim 0.5-0.8 \mathrm{~V}$ compared to the typical charge voltage of $\sim 2 \mathrm{~V}$ in conventional zinc-air battery. The band structure and photoelectrochemical stability of photoelectrodes are found to be key factors determining the charging performance of sunlight-promoted zinc-air batteries. The introduction of photoelectrode as an air electrode opens a facile way for developing integrated single-unit zinc-air batteries that can efficiently use solar energy to overcome the high charging overpotential of conventional zinc-air batteries.

\footnotetext{
${ }^{1}$ Key Laboratory of Advanced Ceramics and Machining Technology (Ministry of Education), School of Materials Science and Engineering, Tianjin University, 300072 Tianjin, China. ${ }^{2}$ Joint School of National University of Singapore and Tianjin University, International Campus of Tianjin University, 350207 Binhai New City, Fuzhou, China. ${ }^{3}$ Department of Mechanical and Industrial Engineering, University of Illinois at Chicago, Chicago, IL 60607, USA. ${ }^{4}$ State Key Laboratory of Metal Matrix Composites, Department of Materials Science and Engineering, Shanghai Jiao Tong University, 200240 Shanghai, China. ${ }^{5}$ These authors contributed equally: Xiaorui Liu, Yifei Yuan. *email: cheng.zhong@tju.edu.cn; wbhu@tju.edu.cn
} 
S olar cell and rechargeable metal-air battery are two totally different systems converting energy of different forms into electricity. Intrinsically, solar cell can only convert light into instant electricity for immediate usage but cannot store energy ${ }^{1}$. Rechargeable metal-air battery, on the other hand, can store (and release) energy repeatedly as needed via oxygen evolution reaction (OER) but this process is essentially plagued by the large overpotential caused by sluggish OER kinetics ${ }^{2}$. Therefore, a combination of these two battery systems would theoretically guarantee a clean and energy-efficient functional integrity, which is however, poorly explored so far.

Among the very few reported studies ${ }^{1,3-7}$, lithium-oxygen battery has been the mostly focused system to be successfully loaded with a photo-responsive electrode where the in situ generated holes possessing positive charges directly ${ }^{5}$ or indirectly ${ }^{4}$ catalyze the OER. Therefore, the notorious large overpotential of the OER has been efficiently suppressed via this synergistic process where solar energy is nominally stored into the rechargeable battery system and further consumed to compensate the energy needed for battery charge. Yet, the high cost and poor safety issues of lithium-oxygen battery make it unsuitable to be coupled with the widely commercialized solar cells aiming at low cost and reliable safety, which thus drives the search for appropriate battery systems.

Among the candidacy of various rechargeable battery technologies, rechargeable zinc-air batteries have attracted great interest thanks to their high energy density $\left(1086 \mathrm{Wh} \mathrm{kg}^{-1}\right.$ in theory), environmental friendliness, earth-abundance of $\mathrm{Zn}$, low cost, and excellent safety enabled by the use of aqueous electrolytes ${ }^{8,9}$. Although primary zinc-air batteries have been commercialized ${ }^{10,11}$, the development of rechargeable zinc-air batteries is still in the early stages with several major challenges that should be addressed. One of the most significant challenges is the high charge overpotential of the battery, which is caused by the practical charge voltage typically above $2 \mathrm{~V}$ despite the calculated theoretical voltage of $1.65 \mathrm{~V}^{8}$. Therefore, the energy efficiency is generally lowered below $60 \%{ }^{9,12}$. Besides, the high charge voltage results in the possible degradation of air electrode due to the side reactions during the charging process, greatly reducing the cycle life of rechargeable zinc-air batteries ${ }^{13,14}$. The large charge overpotential is essentially caused by the sluggish kinetics of oxygen evolution reaction (OER) process that proceeds through four proton-coupled electron transfer steps at the air electrode during the charging process ${ }^{15}$. Therefore, the improvement of the OER kinetics is the central scheme for the further development and commercialization of rechargeable zinc-air battery. In this sense, it should be beneficial to effectively harvest the solar energy using the zinc-air battery system and meanwhile to reduce the charge potential with input electric energy.

In present work, we report a sunlight-promoted rechargeable zinc-air battery by integrating semiconductor photoelectrode as air electrode to significantly lower the charge potential by $\sim 0.5-0.8 \mathrm{~V}$ under sunlight illumination. By utilizing two typical semiconductor photoelectrodes (i.e., $\mathrm{BiVO}_{4}$ and $\alpha-\mathrm{Fe}_{2} \mathrm{O}_{3}$ ) with different band structures, the effect of the band structure of the semiconductor photoelectrode on the charging performance of the zinc-air battery has been clearly demonstrated and the corresponding sunlight-promoted charging mechanism has been proposed. $\mathrm{BiVO}_{4}$ - and $\alpha-\mathrm{Fe}_{2} \mathrm{O}_{3}$-based sunlight-promoted zinc-air batteries exhibit an ultra-low initial charge potential of 1.20 and $1.43 \mathrm{~V}$, respectively, even lower than the theoretical cell voltage of zinc-air batteries. Sunlight-promoted zinc-air batteries with $\alpha$ $\mathrm{Fe}_{2} \mathrm{O}_{3}$ photoelectrode show robust cycling stability due to the high photoelectrochemical stability of $\alpha-\mathrm{Fe}_{2} \mathrm{O}_{3}$ electrode. The concept of sunlight-promoted OER in rechargeable zinc-air battery offers an effective strategy to store the in situ converted energy from the solar cell system and more importantly, to enhance the OER kinetics of zinc-air battery toward its wide application in future.

\section{Results}

Working mechanism of sunlight-promoted rechargeable zinc-air battery. Figure 1a schematically illustrates the basic structure and working mechanism of the sunlight-promoted zinc-air battery. It consists of a $\mathrm{Zn}$ electrode and a semiconductor photoelectrode (i.e., $\mathrm{BiVO}_{4}$ or $\alpha-\mathrm{Fe}_{2} \mathrm{O}_{3}$ ) as an air electrode assembled in alkaline electrolyte (Fig. 1a). The discharging process resemble that in a conventional zinc-air battery: electrochemical oxidation of $\mathrm{Zn}$ to $\mathrm{Zn}^{2+}$ on the $\mathrm{Zn}$ electrode accompanied by the reduction of oxygen on the air electrode gives electricity output ${ }^{9,16}$. The charging process is associated with
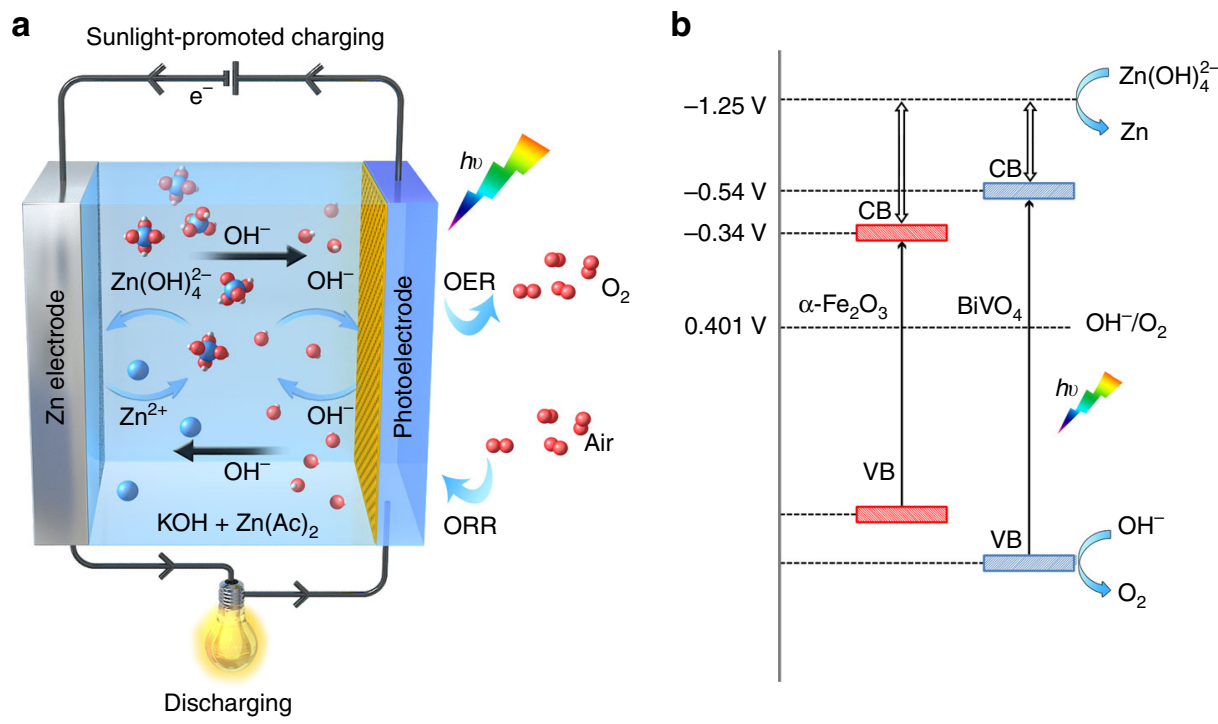

Fig. 1 Schematic sunlight-promoted charge and discharge processes of the sunlight-promoted zinc-air battery. a The scheme of the basic structure and working principle of the sunlight-promoted rechargeable zinc-air battery. $\mathbf{b}$ The proposed mechanism of the sunlight-promoted charging process under solar light illumination 
OER on the air electrode, which has intrinsically sluggish reaction kinetics, resulting in the large overpotential and low energy efficiency. The relevant mechanism of OER is considered as the following processes: ${ }^{17}$ OER reaction begins with the adsorption of $\mathrm{OH}^{-}$and then form adsorbed $\mathrm{OH}$ species (reaction 1). The following step is the reaction of $\mathrm{OH}^{-}$with the adsorbed $\mathrm{OH}$ species to produce $\mathrm{H}_{2} \mathrm{O}$ and adsorbed atomic $\mathrm{O}$ and the release of an electron (reaction 2). After that, the step in the sequence involves the reaction of an $\mathrm{OH}^{-}$with an adsorbed $\mathrm{O}$ atom to form adsorbed $\mathrm{OOH}$ species (reaction 3), which then undergo reaction with additional $\mathrm{OH}^{-}$(reaction 4), leading to the formation of adsorbed $\mathrm{O}_{2}$ and $\mathrm{H}_{2} \mathrm{O}$ and the release of an electron. Adsorbed $\mathrm{O}_{2}$ then desorbs in the last step of the sequence (reaction 5).

$$
\begin{gathered}
\mathrm{M}+\mathrm{OH}^{-} \rightarrow \mathrm{M}-\mathrm{OH}+\mathrm{e}^{-} \\
\mathrm{M}-\mathrm{OH}+\mathrm{OH}^{-} \rightarrow \mathrm{M}-\mathrm{O}+\mathrm{e}^{-}+\mathrm{H}_{2} \mathrm{O} \\
\mathrm{M}-\mathrm{O}+\mathrm{OH}^{-} \rightarrow \mathrm{M}-\mathrm{OOH}+\mathrm{e}^{-} \\
\mathrm{M}-\mathrm{OOH}+\mathrm{OH}^{-} \rightarrow \mathrm{M}-\mathrm{O}_{2}+\mathrm{e}^{-}+\mathrm{H}_{2} \mathrm{O} \\
\mathrm{M}-\mathrm{O}_{2} \rightarrow \mathrm{M}+\mathrm{O}_{2}
\end{gathered}
$$

In comparison with OER process in conventional zinc-air battery, the charging process of sunlight-promoted rechargeable zinc-air battery under illumination is different and significantly facilitated due to the formation of photogenerated holes that have strong oxidative ability and are favorable for proton removal. During the charging process under solar light illumination, the photoelectrode absorbs photons from the light source and generates electron-hole pairs. Then the photogenerated electrons are rapidly injected into the conduction band (CB) of semiconducting photoelectrode and further transferred to the $\mathrm{Zn}$ electrode through the external circuit, resulting in the reduction of $\mathrm{Zn}(\mathrm{OH})_{4}^{2-}$ to $\mathrm{Zn}$ and $\mathrm{OH}^{-}$. The photoexcited holes simultaneously migrate to the photoelectrode surface to oxidize water to oxygen. The reactions for a sunlight-promoted zinc-air battery during discharging and charging are illustrated in Eqs. (6)-(12):

Discharge process: ${ }^{18,19}$

$$
\begin{aligned}
& \text { Zinc electrode : } \mathrm{Zn}+4 \mathrm{OH}^{-} \rightarrow \mathrm{Zn}(\mathrm{OH})_{4}^{2-}+2 \mathrm{e}^{-} E^{0} \\
& =-1.25 \mathrm{~V} \text { versus } \mathrm{SHE} \\
& \mathrm{Zn}(\mathrm{OH})_{4}^{2-} \rightarrow \mathrm{ZnO}+\mathrm{H}_{2} \mathrm{O}+2 \mathrm{OH}^{-} \\
& \text {Air electrode }: \mathrm{O}_{2}+2 \mathrm{H}_{2} \mathrm{O}+4 \mathrm{e}^{-} \rightarrow 4 \mathrm{OH}^{-} E^{0} \\
& =0.401 \mathrm{~V} \text { versus SHE } \\
& \text { Overall }: 2 \mathrm{Zn}+\mathrm{O}_{2} \rightarrow 2 \mathrm{ZnO} E^{0}=1.65 \mathrm{~V}
\end{aligned}
$$

Charge process:

$$
\begin{gathered}
\text { Zinc electrode }: \mathrm{Zn}(\mathrm{OH})_{4}^{2-}+2 \mathrm{e}^{-} \rightarrow \mathrm{Zn}+\mathrm{OH}^{-} \\
\text {Air electrode : Photoelectrode } \stackrel{h v}{\longrightarrow} \mathrm{e}^{-}+\mathrm{h}^{+} \\
4 \mathrm{OH}^{-}+4 \mathrm{~h}^{+} \rightarrow 2 \mathrm{H}_{2} \mathrm{O}+\mathrm{O}_{2}
\end{gathered}
$$

This mechanism is expected to reduce the charge potential of a zinc-air battery through the photooxidation reaction by photogenerated holes to facilitate the OER reaction in the sunlightpromoted charging process. The requirement of photoelectrode in the sunlight-promoted rechargeable zinc-air battery for conversion of $\mathrm{OH}^{-}$to $\mathrm{O}_{2}$ should fulfill the essential condition that the valence band (VB) potential lies higher than the $\mathrm{O}_{2} / \mathrm{OH}^{-}$couple potential $(0.401 \mathrm{~V}$ vs. standard hydrogen electrode (SHE)). As illustrated in the proposed sunlight-promoted charging mechanism (Fig. 1b), the photovoltage generates when the photoelectrode undergoes photoexcitation, which compensates the high charge potential of the zinc-air battery. It is estimated that theoretical sunlight-promoted charge potential equals the potential difference between the $\mathrm{Zn}(\mathrm{OH})_{4}^{2-} / \mathrm{Zn}$ redox potential and the quasi-Fermi level $\left(E_{\mathrm{F}}\right)$ of electrons, which, at its most negative situation, approaches to the conduction band minimum (CBM), in the semiconductor photoelectrode. Based on the above discussion, the band structure (e.g., band edge position and band gap) of the photoelectrode significantly affects the charging performance of the sunlight-promoted zinc-air battery. To better understand the mechanism of sunlight-promoted charging process, for the first time, two typical semiconductor photoelectrodes with different band structures (i.e., $\mathrm{BiVO}_{4}$ and $\alpha-\mathrm{Fe}_{2} \mathrm{O}_{3}$ ) were investigated simultaneously as air electrodes for zinc-air batteries.

Characterization of the photoelectrodes for sunlight-promoted zinc-air battery. The crystal structures of $\mathrm{BiVO}_{4}$ and $\mathrm{Fe}_{2} \mathrm{O}_{3}$ photoelectrodes are analyzed in Fig. 2a, b, respectively. The $\mathrm{BiVO}_{4}$ photoelectrode exhibits a structure identical to monoclinic scheelite $\mathrm{BiVO}_{4}$ (JCPDS Card No. 14-0688) ${ }^{20}$. The $\mathrm{Fe}_{2} \mathrm{O}_{3}$ photoelectrode is indexed to $a$-phase $\mathrm{Fe}_{2} \mathrm{O}_{3}$ (JCPDS Card No. 33-0664 $)^{21}$. Strong (110) diffraction peak implies preferential growth of hematite nanorods in the [110] direction ${ }^{22}$. All the other peaks are indexed to be $\mathrm{SnO}_{2}$ (JCPDS Card No. 46-1088) from the fluorine-doped tin oxide (FTO) substrate. The surface chemical compositions of both $\mathrm{BiVO}_{4}$ and $\alpha-\mathrm{Fe}_{2} \mathrm{O}_{3}$ are confirmed by X-ray photoelectron spectroscopy (XPS). Apparently, the characteristic spin-orbit split of the $\mathrm{Bi} 4 \mathrm{f}_{5 / 2}$ and $\mathrm{Bi} 4 \mathrm{f}_{7 / 2}$ signals (Supplementary Fig. 1a) and V 2 $\mathrm{p}_{1 / 2}$ and V 2 $\mathrm{p}_{3 / 2}$ signals ((Supplementary Fig. 1b) were observed, and they correspond to the typical monoclinic scheelite $\mathrm{BiVO}_{4}{ }^{23}$. In addition, in the survey scan of XPS shown in Supplementary Fig. 1d, e, Fe and O signals can be clearly resolved to represent $\alpha-\mathrm{Fe}_{2} \mathrm{O}_{3}{ }^{24}$. Scanning electron microscopy (SEM) reveals that the obtained $\mathrm{BiVO}_{4}$ product consists of interconnected columnar-like particles with an average particle size of $\sim 110 \mathrm{~nm}$, forming a three-dimensional (3D) porous network (Fig. 2c). The thickness of the $\mathrm{BiVO}_{4}$ film is estimated to be $\sim 650 \mathrm{~nm}$ according to the cross-sectional SEM (Supplementary Fig. 2a). SEM image in Fig. $2 d$ shows that the $\alpha-\mathrm{Fe}_{2} \mathrm{O}_{3}$ film grown on the FTO substrate is composed of nanorods with an average diameter of $\sim 70 \mathrm{~nm}$. Cross-sectional SEM image indicates that $\alpha$ $\mathrm{Fe}_{2} \mathrm{O}_{3}$ nanorods are aligned roughly vertically to the substrates and yield an average length of $\sim 350 \mathrm{~nm}$ (Supplementary Fig. 2b).

Figure $3 \mathrm{a}$ shows the current density-potential curves for the OER on $\mathrm{BiVO}_{4}$ and $\alpha-\mathrm{Fe}_{2} \mathrm{O}_{3}$ electrodes in the dark and under $\mathrm{AM}$ $1.5 \mathrm{G}$ simulated solar light at $100 \mathrm{~mW} \mathrm{~cm}^{-2}$. Both $\mathrm{BiVO}_{4}$ and $\alpha-$ $\mathrm{Fe}_{2} \mathrm{O}_{3}$ electrodes exhibit small current density and high onset potential (defined as the potential where photocurrent reaches $0.1 \mathrm{~mA} \mathrm{~cm}^{-2}$ ) above $\sim 1.4 \mathrm{~V}$ for water oxidation in the dark condition. In sharp contrast, the $\mathrm{BiVO}_{4}$ and $\alpha-\mathrm{Fe}_{2} \mathrm{O}_{3}$ electrodes show very low onset potential below $\sim 0.9 \mathrm{~V}$ under simulated sunlight illumination. Furthermore, the photocurrent increases linearly with the increasing voltage and achieves high values of 0.79 and $0.60 \mathrm{~mA} \mathrm{~cm}^{-2}$ at $1.23 \mathrm{~V}$ vs. RHE, respectively, which are more than one order of magnitude larger than those under the dark condition. This indicates that the application of photoelectrodes dramatically accelerate water oxidation kinetics under illumination. The charge-transfer properties of the photoanodes were further investigated by electrochemical impedance spectroscopy (EIS) (Supplementary Fig. 3). In dark, both photoanodes show one semicircle reflecting the charge-transfer resistance at the electrode surface (Supplementary Fig. 3a) 25,26 . Under 
a
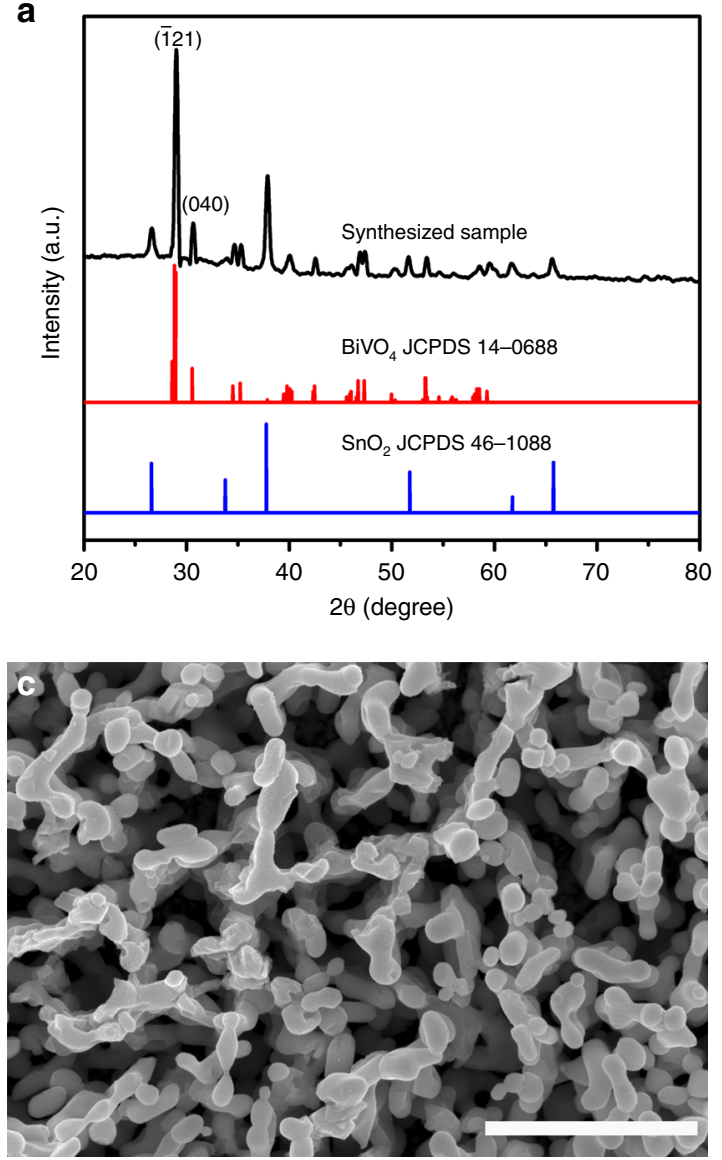

b
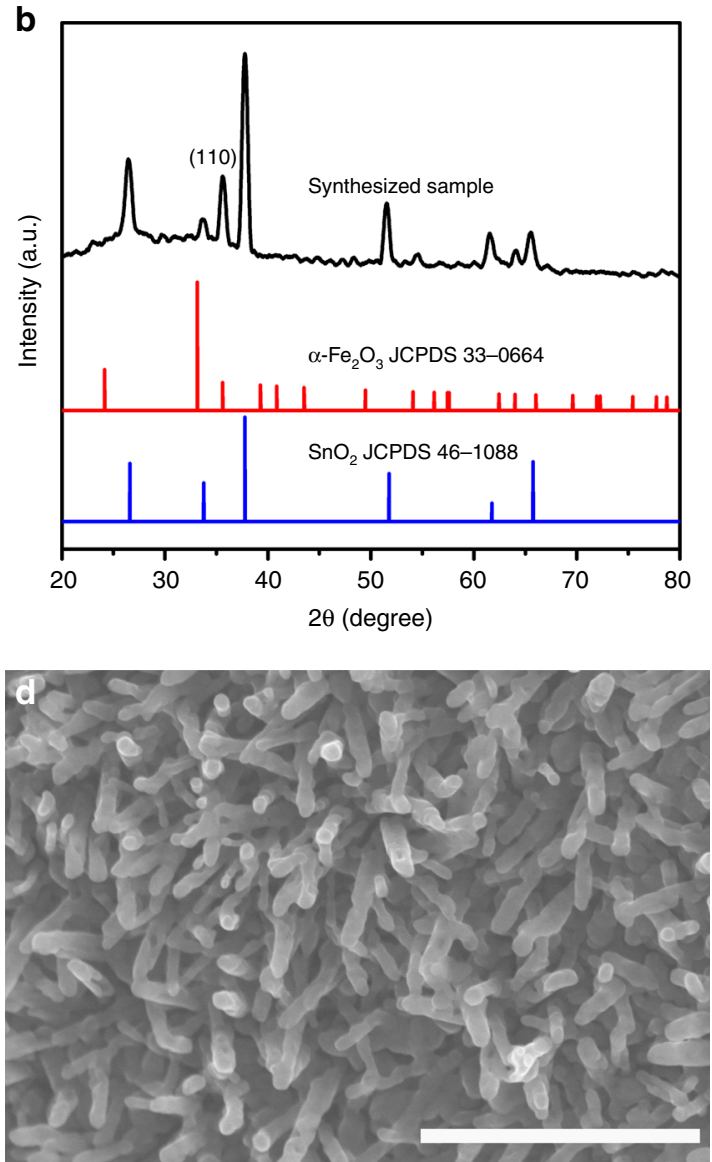

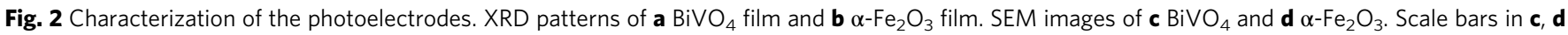
are $1 \mu \mathrm{m}$

illumination, Nyquist plots show two semicircles for both photoanodes. The arcs observed in the high and the low frequencies correspond to the bulk and surface charge-transfer processes, respectively ${ }^{26,27}$. The semicircles obtained under illumination have much smaller radius than those in the dark, indicating much smaller charge-transfer resistance due to increased carrier density when the semiconductor photoelectrodes absorbs photons, confirming the photo-responsive property of the photoelectrodes. Moreover, $\mathrm{BiVO}_{4}$ electrode has a smaller semicircle radius than $\alpha-\mathrm{Fe}_{2} \mathrm{O}_{3}$ electrode, implying its better charge-transfer efficiency.

To evaluate the band structure of $\mathrm{BiVO}_{4}$, Mott-Schottky (M-S) analysis was performed at $1 \mathrm{kHz}$ (Fig. $3 \mathrm{~b}, \mathrm{c}$ ). The positive slope of the $\mathrm{M}-\mathrm{S}$ plots suggests $\mathrm{n}$-type semiconducting nature of both $\mathrm{BiVO}_{4}$ and $\alpha-\mathrm{Fe}_{2} \mathrm{O}_{3}$ electrodes. The flat band potential $\left(E_{\mathrm{FB}}\right)$ and donor densities $\left(N_{\mathrm{D}}\right)$ of two electrodes are calculated based on the slopes of $\mathrm{M}-\mathrm{S}$ plots $^{28}$, which are $0.17 \mathrm{~V}$ (vs. RHE) and $2.18 \times$ $10^{20} \mathrm{~cm}^{-3}$ for $\mathrm{BiVO}_{4}$ and 0.47 and $1.25 \times 10^{19} \mathrm{~cm}^{-3}$ for $\alpha-\mathrm{Fe}_{2} \mathrm{O}_{3}$. It should be noted that the $\mathrm{M}-\mathrm{S}$ analysis is derived from a planar electrode model ${ }^{29}$ and therefore these values are only for the purpose of relative comparison. Compared to $\alpha-\mathrm{Fe}_{2} \mathrm{O}_{3}$ the negative shift of $E_{\mathrm{FB}}$ and larger $\mathrm{N}_{\mathrm{D}}$ of $\mathrm{BiVO}_{4}$ electrode indicate that the Fermi level is closer to the $\mathrm{CB}^{30,31}$, leading to more significant band bending in the space charge region than that of $\alpha-\mathrm{Fe}_{2} \mathrm{O}_{3}$ due to a larger difference between the Fermi level of $\mathrm{BiVO}_{4}$ photoelectrode and the redox potential of the electrolyte. This facilitates the charge separation efficiency of the photogenerated charge carriers 32,33 , which is consistent with the higher photocurrent density of $\mathrm{BiVO}_{4}$ electrode compared to $a-\mathrm{Fe}_{2} \mathrm{O}_{3}$ electrode (Fig. 3a).
The photoelectrochemical stability is another important factor affecting the life of the batteries for practical applications, which was investigated by chronoamperometry measurements under illumination as shown in Fig. 3d. Clearly, $\alpha-\mathrm{Fe}_{2} \mathrm{O}_{3}$ photoelectrode exhibits excellent stability in alkaline electrolyte, retaining nearly $100 \%$ of its original activity after $5 \mathrm{~h}$. In addition, the photocurrent density-potential curve of the $a-\mathrm{Fe}_{2} \mathrm{O}_{3}$ photoelectrode remains almost unchanged after the stability test (Supplementary Fig. 4b), confirming its high stability during OER. However, the $\mathrm{BiVO}_{4}$ photoelectrode suffers $84.6 \%$ decrease in the photocurrent density within only $10 \mathrm{~min}$ of operation, indicating the severe photocorrosion in the $\mathrm{BiVO}_{4}$ photoelectrode. The structure and morphology of two samples after the stability test are further explored. There is no noticeable change in XRD pattern of $a-\mathrm{Fe}_{2} \mathrm{O}_{3}$ after stability test (Supplementary Fig. 5b). The overall morphology of $\alpha-\mathrm{Fe}_{2} \mathrm{O}_{3}$ is well maintained (Fig. $2 \mathrm{~d}$ vs. Supplementary Fig. 5d). On the contrary, the XRD peak intensity of the $\mathrm{BiVO}_{4}$ photoelectrode remarkably decreases after the stability test (Supplementary Fig. 5a). The SEM image after stability test also shows the dissolution of $\mathrm{BiVO}_{4}$ (Supplementary Fig. 5c), suggesting the existing electrode photocorrosion. This suggests that the quick decrease in the photocurrent of $\mathrm{BiVO}_{4}$ compared to $\alpha-\mathrm{Fe}_{2} \mathrm{O}_{3}$ under illumination is attributed to the photocorrosion of $\mathrm{BiVO}_{4}$ photoelectrode.

Band structure of the photoelectrode. The optical absorption properties of $\mathrm{BiVO}_{4}$ and $\alpha-\mathrm{Fe}_{2} \mathrm{O}_{3}$ photoelectrodes were investigated using ultraviolet-visible (UV-vis) absorption spectra as shown in Fig. 4a. Both photoelectrodes show obvious absorption 

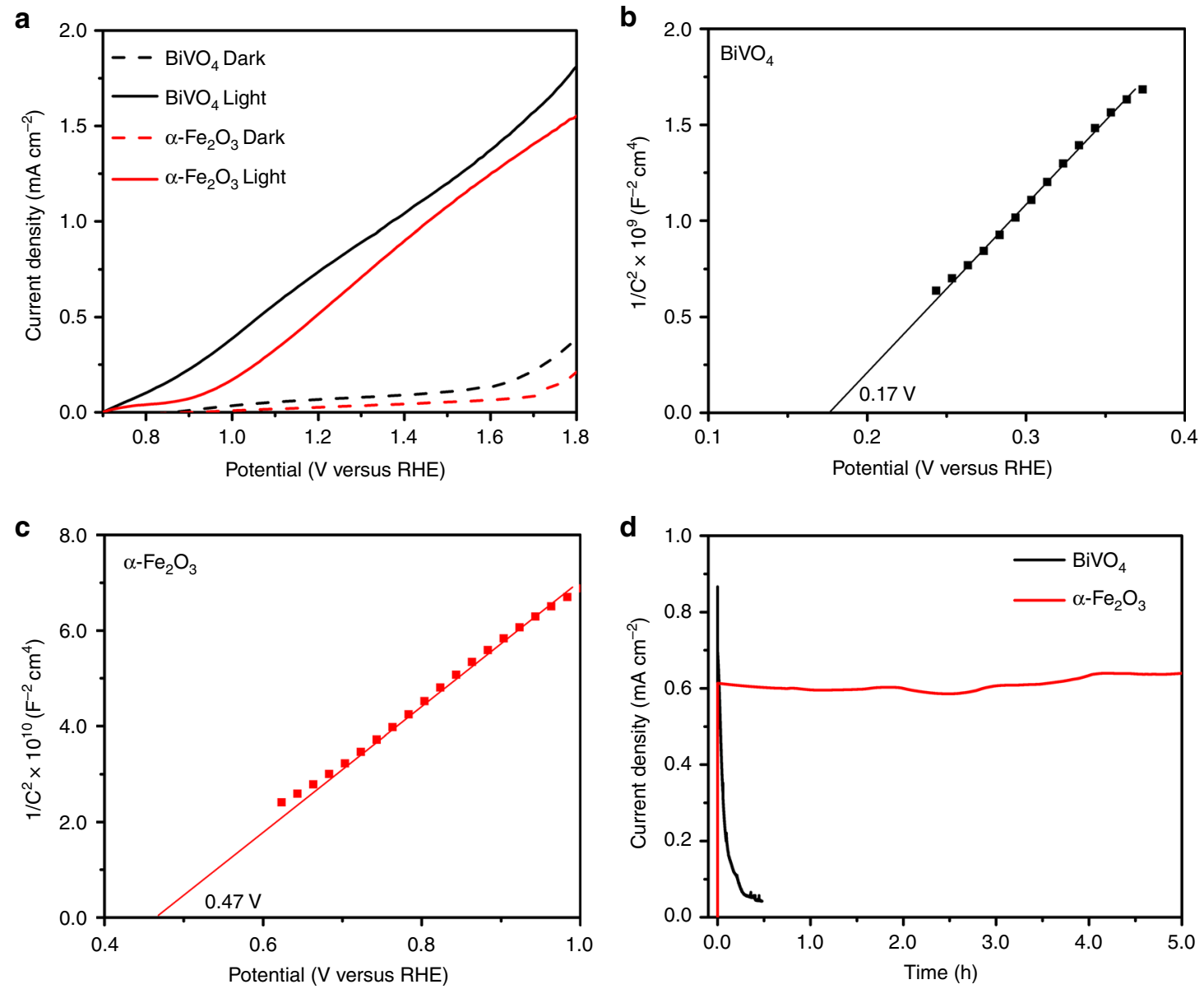

Fig. 3 Photoelectrochemical performance of the photoelectrodes. a Current density-potential curves of $\mathrm{BiVO}_{4}$ and $\alpha-\mathrm{Fe}_{2} \mathrm{O}_{3}$ measured in $1 \mathrm{M} \mathrm{KOH}$ (pH $=$ 13.6) in the dark and under AM $1.5 \mathrm{G}, 100 \mathrm{~mW} \mathrm{~cm}-2$ illumination. Mott-Schottky plots of the b BiVO4 and $\mathbf{c} \alpha-\mathrm{Fe}_{2} \mathrm{O}_{3}$ at an $\mathrm{AC}$ frequency of $1 \mathrm{kHz}$ in the dark. d Current density-time curves of the $\mathrm{BiVO}_{4}$ and $\alpha-\mathrm{Fe}_{2} \mathrm{O}_{3}$ photoelectrodes under illumination at $1.23 \mathrm{~V}$ vs. $\mathrm{RHE}$

of visible light. The absorption edge of $\mathrm{BiVO}_{4}$ and $\alpha-\mathrm{Fe}_{2} \mathrm{O}_{3}$ extends to $504 \mathrm{~nm}$ and $590 \mathrm{~nm}$, corresponding to the band gap energy $\left(E_{\mathrm{g}}\right)$ of 2.46 and $2.10 \mathrm{eV}$, respectively (Supplementary Fig. 6). The VB positions of the two photoelectrodes were measured by X-ray photoelectron spectroscopy (XPS) (Fig. 4b). The positions of the valence band maximum (VBM) relative to the Fermi level $\left(E_{\mathrm{F}}\right)$ can be estimated by linear extrapolation of the leading edges in the spectra ${ }^{34}$, which are deduced to be 2.11 and $1.70 \mathrm{eV}$ for $\mathrm{BiVO}_{4}$ and $\alpha-\mathrm{Fe}_{2} \mathrm{O}_{3}$, respectively.

To further analyze the band structure, the surface work function of $\alpha-\mathrm{Fe}_{2} \mathrm{O}_{3}$ and $\mathrm{BiVO}_{4}$ was measured using ultraviolet photoelectron spectroscopy (UPS). The work function of $\mathrm{BiVO}_{4}$ and $\alpha-\mathrm{Fe}_{2} \mathrm{O}_{3}$ is 5.05 and $5.30 \mathrm{eV}$, respectively (Fig. 4c, d). Furthermore, the UPS data is combined with the values of $E_{\mathrm{g}}$ and VBM to calculate the positions of the $\mathrm{CB}$ edge ${ }^{35}$, which lies below $0.26 \mathrm{~V}$ and $0.46 \mathrm{~V}$ reference to $\mathrm{SHE}$ for $\mathrm{BiVO}_{4}$ and $\alpha-\mathrm{Fe}_{2} \mathrm{O}_{3}$, respectively (assuming SHE to be positioned $4.44 \mathrm{eV}$ below the vacuum energy). Based on the charging mechanism mentioned above, the $\mathrm{CB}$ edge combined with $\mathrm{Zn}(\mathrm{OH})_{4}^{2-} / \mathrm{Zn}$ redox potential can be used to predict the theoretical charge voltage of the sunlight-promoted zinc-air batteries, as presented in Fig. 1b. This will be further discussed and confirmed in combination with performance studies of sunlight-promoted zinc-air batteries.

The performance of sunlight-promoted zinc-air battery. To demonstrate the potential application of photoelectrode as an air electrode, we assembled a single-body-structured zinc-air battery using the semiconductor photoelectrode. The charging curves of zinc-air battery in the dark and under illumination based on $\mathrm{BiVO}_{4}$ and $\alpha-\mathrm{Fe}_{2} \mathrm{O}_{3}$ photoelectrodes are shown in Fig. 5a, b. As expected, the introduction of the light dramatically reduces the charge potential of the zinc-air battery. Upon illumination, the charge voltage of $\mathrm{BiVO}_{4}$-based zinc-air battery achieves a very low initial charging voltage of $\sim 1.20 \mathrm{~V}$ corresponding to the voltage reduction of $\sim 0.76 \mathrm{~V}$ (Fig. $5 \mathrm{a}$ ), which translates to energy savings of close to $38.8 \%$ (Supplementary Table 1). This charging voltage value is significantly lower than the theoretical working voltage $(1.65 \mathrm{~V})$ of the zinc-air battery, and is also a record-low value among the reported literature to the best of our knowledge. However, the charge potential keeps increasing to get close to the charge potential without illumination, which is attributed to the photocorrosion of $\mathrm{BiVO}_{4}$ electrode (Fig. 3d). For $\alpha-\mathrm{Fe}_{2} \mathrm{O}_{3}$-based zinc-air battery under illumination, the charge potential is also obviously lower than the theoretical working potential of the zinc-air battery with a remarkable reduction of $\sim 0.54 \mathrm{~V}$ (Fig. 5b), corresponding to energy savings of $27.4 \%$ (Supplementary Table 1). Due to the high photoelectrochemical stability of $\alpha$ $\mathrm{Fe}_{2} \mathrm{O}_{3}$ electrode, the battery exhibits a stable charging plateau under illumination. Moreover, the charging voltage of the battery increases instantly once the light is off while the charging potential drops rapidly with the illumination (Supplementary Fig. 7), confirming the achievement of such a low charge potential owing to the effective utilization of the solar energy and also suggesting the battery possesses a fast light-response. This significant decrease in the charge potential can be related to the 

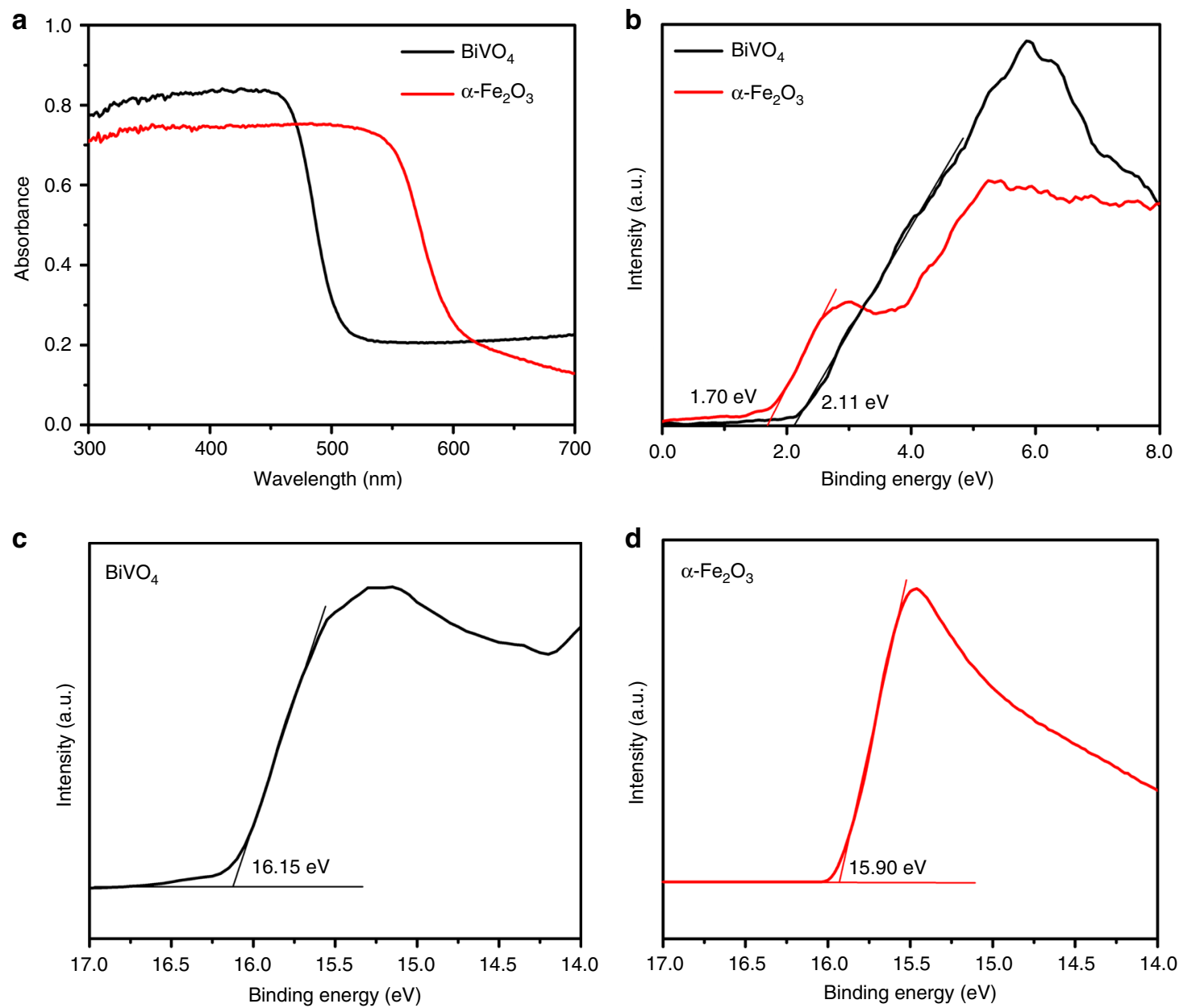

Fig. 4 Band structures of the photoelectrodes. a Ultraviolet-visible absorption spectra of the $\mathrm{BiVO}_{4}$ and $\alpha-\mathrm{Fe}_{2} \mathrm{O}_{3}$ photoelectrodes. $\mathbf{b}$ XPS valence band spectra of the $\mathrm{BiVO}_{4}$ and $\alpha-\mathrm{Fe}_{2} \mathrm{O}_{3}$ photoelectrodes. Work function data of $\mathbf{c} \mathrm{BiVO}_{4}$ and $\mathbf{d} \alpha-\mathrm{Fe}_{2} \mathrm{O}_{3}$ are from UPS measurements

band structure of the $\mathrm{BiVO}_{4}$ and $\alpha-\mathrm{Fe}_{2} \mathrm{O}_{3}$ (Fig. 1b). Both the negative shift of the onset oxidation potential (Fig. 3a) and the lowering of the charge potential are attributed to the negative shift of the quasi-Fermi level of photoelectrodes compared to the $\mathrm{OH}^{-} / \mathrm{O}_{2}$ redox potential under illumination. Since the OER process is achieved by the photogenerated holes in photoelectrode rather than direct oxidation of $\mathrm{OH}^{-}$under illumination, $\mathrm{BiVO}_{4}$ with a more negative CBM exhibits lower charge potential at the initial charging stage. Ideally, the band edge position is $\mathrm{pH}$ dependent and follows the Nernstian $\mathrm{pH}$ dependence in aqueous solutions (a change of the $\mathrm{pH}$ value shifts the potential by $\sim 59$ $\mathrm{mV}$ per $\left.\mathrm{pH}^{36,37}\right)$. Based on the estimated $\mathrm{CBM}$ value $(-0.54 \mathrm{~V}$ for $\mathrm{BiVO}_{4} ;-0.34 \mathrm{~V}$ for $\alpha-\mathrm{Fe}_{2} \mathrm{O}_{3}$ at electrolyte $\left.\mathrm{pH}=13.6\right)$ and the discussion in Fig. 1b, the theoretical charge potential of the sunlight-promoted zinc-air battery based on $\mathrm{BiVO}_{4}$ and $\alpha-\mathrm{Fe}_{2} \mathrm{O}_{3}$ is expected to be 0.71 and $0.91 \mathrm{~V}$, respectively. The initial charge potential of $\mathrm{BiVO}_{4}$-based zinc-air battery is $\sim 0.23 \mathrm{~V}$ lower than the $a-\mathrm{Fe}_{2} \mathrm{O}_{3}$-based one, which matches well with the theoretical value of $0.20 \mathrm{~V}$. Considering the factors including energy gap between the photoelectrode $\mathrm{CBM}$ and the $E_{\mathrm{F}}$ of electrons under working condition, the charge recombination occurring in the photoelectrode-electrolyte interface, and the internal series resistance within the device, it is reasonable to obtain a higher actual charging voltage than the theoretical value.

Figure $5 \mathrm{c}$, d show the sunlight-promoted charging curves at different current densities, where the polarization degree does not drastically increase. Even with the current density increased by 5 times to $0.5 \mathrm{~mA} \mathrm{~cm}^{-2}$, the initial charging voltage $(\sim 1.35 \mathrm{~V})$ of
$\mathrm{BiVO}_{4}$-based battery is still much lower than the theoretical working voltage $(1.65 \mathrm{~V})$ of the zinc-air system; $\alpha-\mathrm{Fe}_{2} \mathrm{O}_{3}$-based battery gives a larger charging potential of $\sim 1.64 \mathrm{~V}$, which is very close to the theoretical working voltage. The discharge-charge polarization curves for zinc-air battery using $\mathrm{BiVO}_{4}$ and $\alpha-\mathrm{Fe}_{2} \mathrm{O}_{3}$ as the air electrode with and without light illumination are shown in Supplementary Fig. 8. The light illumination significantly decreases the charge potential for both batteries especially at low current densities, resulting from the remarkably improved OER performance under illumination (Fig. 3a). Besides, $\mathrm{BiVO}_{4}$ delivers a lower charging voltage compared to $\alpha-\mathrm{Fe}_{2} \mathrm{O}_{3}$ due to the higher OER photoelectrocatalytic activity of $\mathrm{BiVO}_{4} \cdot \mathrm{BiVO}_{4^{-}}$and $\alpha-$ $\mathrm{Fe}_{2} \mathrm{O}_{3}$-based batteries exhibit similar discharge behaviors in dark and under illumination, which is consistent with the oxygen reduction reaction (ORR) performance of the two photoelectrodes (Supplementary Fig. 9). To demonstrate the practical applications of the zinc-air batteries, the batteries were tested via long-term galvanostatic discharge (Supplementary Fig. 10). The initial discharge voltage platforms of the two batteries are similar, in accordance with the similar ORR performance between $\mathrm{BiVO}_{4}$ and $\mathrm{a}-\mathrm{Fe}_{2} \mathrm{O}_{3}$ electrodes (Supplementary Fig. 9). $\mathrm{BiVO}_{4}$-based battery shows distinct decrease in the voltage after discharge of $\sim 10 \mathrm{~h}$ while $\mathrm{a}-\mathrm{Fe}_{2} \mathrm{O}_{3}$-based battery is relatively stable during the whole discharge for $30 \mathrm{~h}$. This is attributed to the different chemical stability of $\mathrm{BiVO}_{4}$ and $\alpha-\mathrm{Fe}_{2} \mathrm{O}_{3}$ in the electrolyte, suggesting the applicable features of $\alpha-\mathrm{Fe}_{2} \mathrm{O}_{3}$-based zinc-air battery. Based on the consumed zinc electrode, the discharge gravimetric capacity and energy density of zinc-air battery using 
a

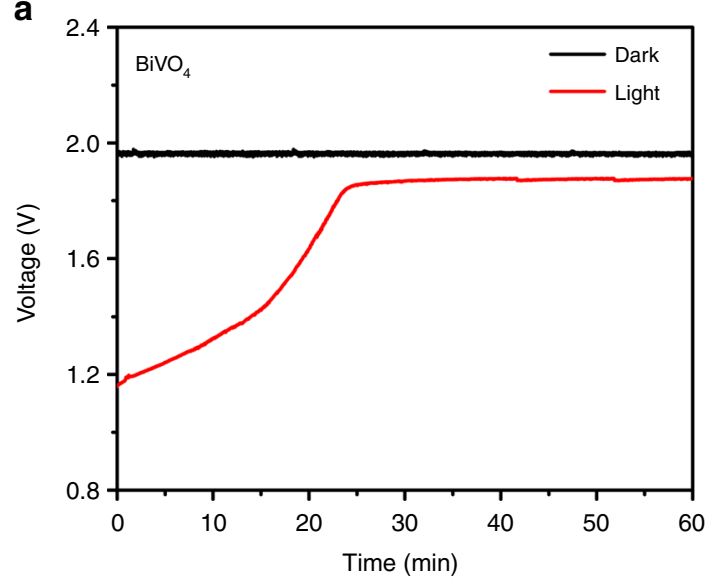

C

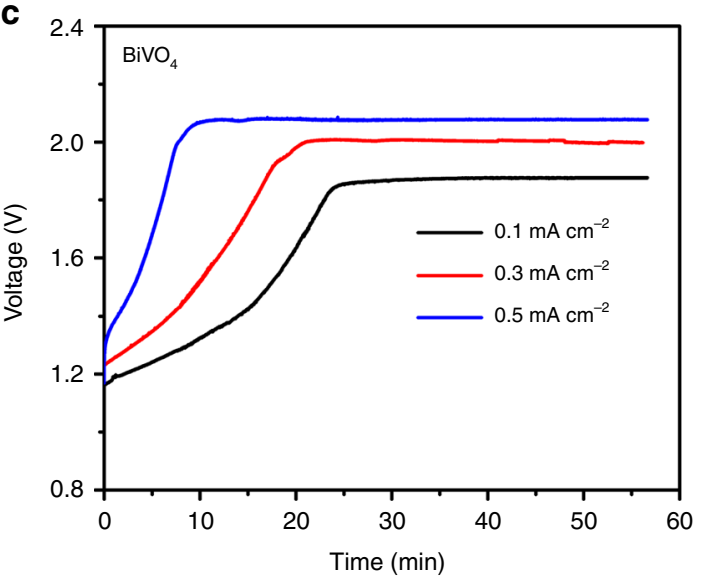

e

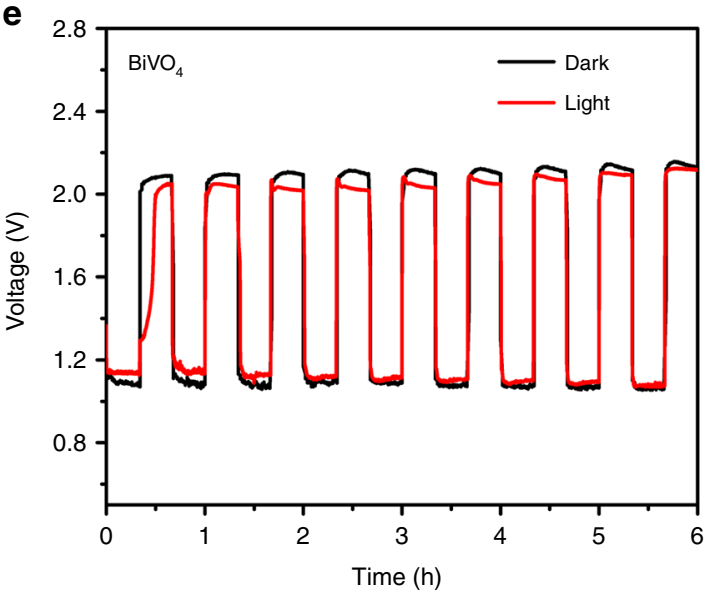

b

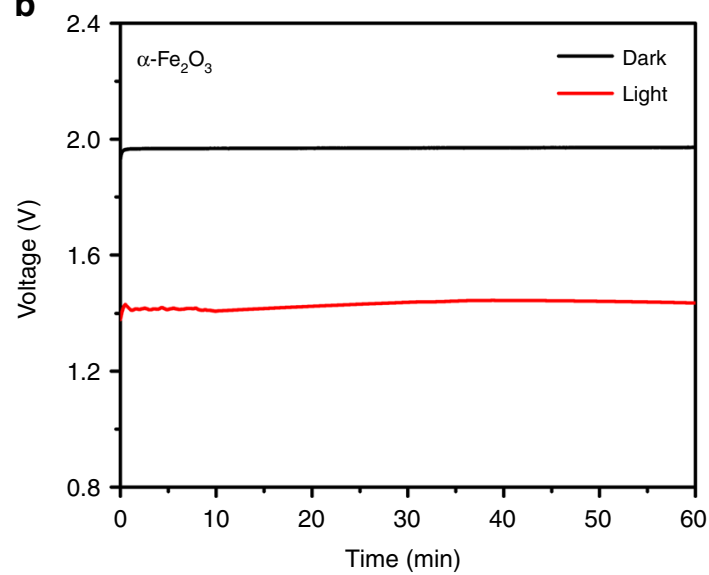

d

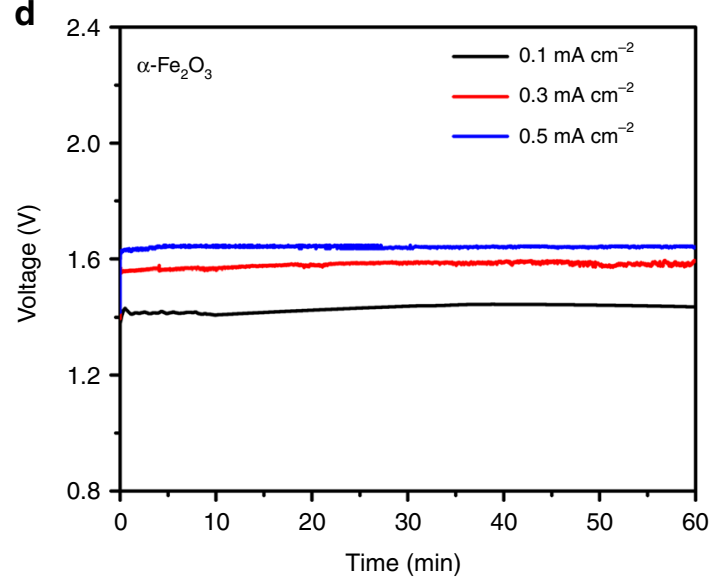

f

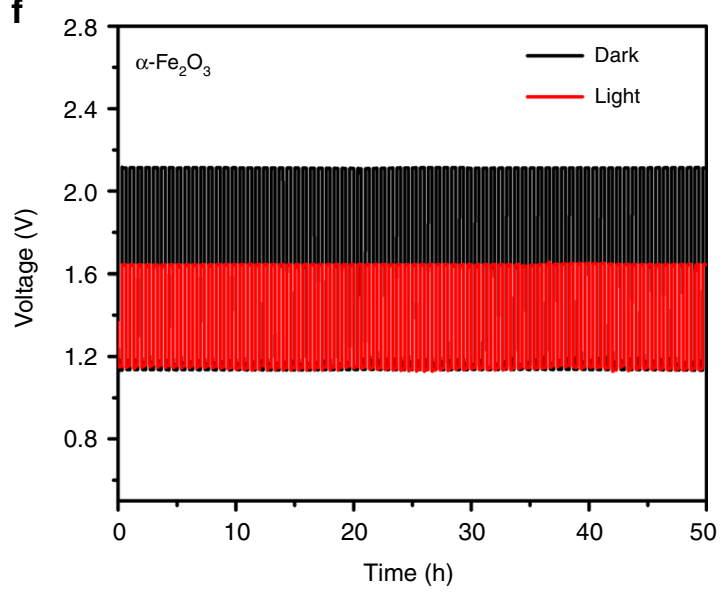

Fig. 5 Electrochemical characterizations of the sunlight-promoted rechargeable zinc-air battery. The charging curves of a zinc-air battery in the dark and under illumination with $\mathbf{a} \mathrm{BiVO}_{4}$ and $\mathbf{b} \alpha-\mathrm{Fe}_{2} \mathrm{O}_{3}$ air photoelectrode, respectively, at a current density of $0.1 \mathrm{~mA} \mathrm{~cm}{ }^{-2}$. The charging curves of a Zinc-air battery with $\mathbf{c} \mathrm{BiVO}_{4}$ and $\mathbf{d} \alpha-\mathrm{Fe}_{2} \mathrm{O}_{3}$ air photoelectrode, respectively, at the current density of $0.1,0.3$, and $0.5 \mathrm{~mA} \mathrm{~cm}{ }^{-2}$ under illumination. Cycling performance of sunlight-promoted rechargeable zinc-air battery in the dark and under illumination with e $\mathrm{BiVO}_{4}$ and $\mathbf{f} \alpha-\mathrm{Fe}_{2} \mathrm{O}_{3}$ air photoelectrode, respectively, at a current density of $0.5 \mathrm{~mA} \mathrm{~cm}^{-2}$

the $\alpha-\mathrm{Fe}_{2} \mathrm{O}_{3}$ are $598.7 \mathrm{mAh} \mathrm{g}_{\mathrm{Zn}}{ }^{-1}$ and $694.5 \mathrm{mWh} \mathrm{g}_{\mathrm{Zn}}{ }^{-1}$ at 0.5 $\mathrm{mA} \mathrm{cm}{ }^{-2}$ with $46 \mathrm{mg}$ consumed $\mathrm{Zn}$. The gravimetric capacity and energy density of $\mathrm{BiVO}_{4}$-based zinc-air battery are 538.5 $\mathrm{mAh} \mathrm{g}_{\mathrm{Zn}}{ }^{-1}$ and $540.1 \mathrm{mWh}_{\mathrm{Zn}}{ }^{-1}$ respectively, at $0.5 \mathrm{~mA} \mathrm{~cm}^{-2}$ with $39 \mathrm{mg}$ consumed $\mathrm{Zn}$. To investigate the cycling stability, the discharge-charge tests were performed in the dark and under illumination separately. As shown in Fig. 5e, upon illumination, zinc-air battery based on the $\mathrm{BiVO}_{4}$ air photoelectrode exhibits a low charge voltage of $\sim 1.30 \mathrm{~V}$ at the first $3 \mathrm{~min}$, corresponding to an extremely small discharge-charge voltage gap of $\sim 0.16 \mathrm{~V}$ and a very high energy efficiency of $\sim 87.7 \%$. Unfortunately, the charging voltage quickly increases to $\sim 2.12 \mathrm{~V}$ and the discharging voltage also gradually decreases to $\sim 1.07 \mathrm{~V}$ after $6 \mathrm{~h}$ test, corresponding to the increase of voltage gap to $1.05 \mathrm{~V}$ and the 
decrease of energy efficiency to $50.5 \%$ after the test. The observed performance degradation is due to the severe photocorrosion of $\mathrm{BiVO}_{4}$ (Fig. 3d, Supplementary Fig. 5a, c). In sharp contrast, the battery using $\alpha-\mathrm{Fe}_{2} \mathrm{O}_{3}$ air photoelectrode achieves a stable cycling performance with the charge and discharge potential plateaus at $\sim 1.64$ and $\sim 1.15 \mathrm{~V}$, respectively, under illumination during the cycles for $\sim 50 \mathrm{~h}$ (Fig. 5f). This corresponds to an impressively high energy efficiency of $\sim 70.3 \%$ compared to the $\alpha-\mathrm{Fe}_{2} \mathrm{O}_{3}$-based zinc-air battery of $\sim 54.5 \%$ in the dark condition.

To further analyze the limiting factor for the long-term cycling of $\alpha-\mathrm{Fe}_{2} \mathrm{O}_{3}$-based zinc-air battery, the new reassembled zinc-air battery was fabricated based on the disassembled $a-\mathrm{Fe}_{2} \mathrm{O}_{3}$ electrode from the failed battery by replacing the fresh $\mathrm{KOH}$ electrolyte and new zinc electrode. Interestingly, the new reassembled zinc-air battery can further cycle for $\sim 40 \mathrm{~h}$ (Supplementary Fig. 11), indicating the excellent stable performance of $\mathrm{a}-\mathrm{Fe}_{2} \mathrm{O}_{3}$ electrode, which is not the limiting factor for the long-term cycling. According to the working mechanisms of the battery, reactions of $\mathrm{Zn}$ electrode during the discharge process of zinc-air battery are accompanied with consumption of $\mathrm{OH}^{-}$ and formation of insoluble $\mathrm{ZnO}$, leading to passivation of $\mathrm{Zn}$ electrode (reactions (6)-(7)), which will increase the resistance of the zinc-air battery and make it failure to discharge. Therefore, the limiting factor for the long-term cycling of zinc-air battery is the passivation of zinc electrode in alkaline electrolyte. The structure and morphology of two samples after the cycling test are further explored. The transmission electron microscopy (TEM) images for $\mathrm{a}-\mathrm{Fe}_{2} \mathrm{O}_{3}$ and $\mathrm{BiVO}_{4}$ materials before and after cycling tests are analyzed. It can be seen that the surface morphology of $\mathrm{BiVO}_{4}$ electrode exhibits significant dissolution after cycling test compared to the initial electrode, but the high-resolution TEM (HRTEM) images of the $\mathrm{BiVO}_{4}$ electrode remains a lattice spacing of $0.46 \mathrm{~nm}$, which is well consistent with the (011) plane of crystalline $\mathrm{BiVO}_{4}$ (Supplementary Fig. 12). With respect to the $\alpha-\mathrm{Fe}_{2} \mathrm{O}_{3}$ electrode, the TEM images for $\alpha-\mathrm{Fe}_{2} \mathrm{O}_{3}$ before and after cycling test show the same nanorod morphology (Supplementary Fig. 13). Moreover, the HRTEM images (Supplementary Fig. 13) of $\alpha-\mathrm{Fe}_{2} \mathrm{O}_{3}$ before and after cycling display lattice fringes with an inter-planar spacing of $0.25 \mathrm{~nm}$, matching well with the (110) plane of $\alpha-\mathrm{Fe}_{2} \mathrm{O}_{3}$. The TEM results for $\alpha-\mathrm{Fe}_{2} \mathrm{O}_{3}$ and $\mathrm{BiVO}_{4}$ materials after long-term cycling tests further indicate the high stability of $\alpha-\mathrm{Fe}_{2} \mathrm{O}_{3}$. In addition, XPS tests for photoelectrodes before and after cycling test are conducted to understand the possible chemical changes of the materials. The XPS for $\mathrm{BiVO}_{4}$ before and after the cycling performance is provided in Supplementary Fig. 1a-c, which shows the remarkable decrease of XPS peak intensity, suggesting the sever dissolution of $\mathrm{BiVO}_{4}$ electrode during the cycling test. In contrast, there is no noticeable change in XPS spectra of $\alpha-\mathrm{Fe}_{2} \mathrm{O}_{3}$ after stability test (Supplementary Fig. 1d-f), indicating the well maintained chemical compositions. Moreover, based on the EIS results of photoelectrodes (Supplementary Fig. 14), the charge-transfer resistance of $\mathrm{BiVO}_{4}$ increases compared to the initial electrode (Supplementary Fig. 3) after cycling test especially under illumination, which is close to that in the dark. This is due to the severe photocorrosion in the $\mathrm{BiVO}_{4}$, resulting in the performance degradation. In contrast, the charge-transfer resistance of $\alpha-\mathrm{Fe}_{2} \mathrm{O}_{3}$ electrode remains almost the same after cycling test compared to the initial electrode (Supplementary Fig. 3), indicating its remarkable stability. The above characterization results for $\alpha-\mathrm{Fe}_{2} \mathrm{O}_{3}$ and $\mathrm{BiVO}_{4}$ materials after long-term cycling tests further highlight the performance stability of $a-\mathrm{Fe}_{2} \mathrm{O}_{3}$. Furthermore, after the full discharge of $66 \mathrm{~h}$, the $\alpha-\mathrm{Fe}_{2} \mathrm{O}_{3}$-based zinc-air battery could be charged back under illumination. The recharged battery can continue to function over further cycling tests under illumination although there is a small decay of charge and discharge voltage which is due to the long-term consumption of zinc and electrolyte (Supplementary Fig. 15), demonstrating the sunlight-promoted charge process. Furthermore, we have replaced zinc electrode with a copper current collector for further confirming the sunlight-promoted charging process. Interestingly, it can be seen that $\mathrm{Zn}$ is deposited onto the copper current collector for the $\alpha-\mathrm{Fe}_{2} \mathrm{O}_{3}$-based zinc-air battery after sunlightpromoted charging of $3 \mathrm{~h}$ at $1 \mathrm{~mA} \mathrm{~cm}^{-2}$. According to the XRD results (Supplementary Fig. 16a), the deposited $\mathrm{Zn}$ is indexed to metallic Zn (JCPDS Card No. 04-0831). All the other peaks are indexed to be metallic Cu (JCPDS Card No. 04-0836) from the copper substrate. In addition, the composition of deposited $\mathrm{Zn}$ is analyzed by energy-dispersive X-ray spectroscopy (EDX) (Supplementary Figs. 16b, c), which also suggests the successful deposition of $\mathrm{Zn}$ on the copper current collector, again confirming the sunlight-promoted charging process. All the results clearly highlight the promising $\alpha-\mathrm{Fe}_{2} \mathrm{O}_{3}$ photoelectrode as an efficient air electrode utilizing solar energy for sunlightpromoted zinc-air battery, and also demonstrate that the band structure and the photoelectrochemical/chemical stability of photoelectrode play a significant role in determining the battery performance including the charging performance, energy efficiency and lifetime. As discussed above, the concept of sunlightpromoted OER in rechargeable zinc-air battery offers an effective strategy by utilizing solar energy to facilitate the OER kinetics of metal-air battery toward its wide application in future. To demonstrate its promising application in other metal-air batteries, we assembled the Fe-air battery based on the photoelectrode (e.g., $\boldsymbol{\alpha}-\mathrm{Fe}_{2} \mathrm{O}_{3}$ ) as an example. The "lightresponse" charging feature of the Fe-air battery is shown in Supplementary Fig. 17. Excitingly, the sunlight-promoted rechargeable $\mathrm{Fe}$-air batteries exhibit charge potential of $\sim 1.26 \mathrm{~V}$ based on $\alpha-\mathrm{Fe}_{2} \mathrm{O}_{3}$. Once the sunlight is cut off, it can be seen that the applied voltage increases immediately. The example of the sunlight-promoted $\mathrm{Fe}$-air batteries further demonstrates that the concept of utilizing solar energy to improve the oxygen evolution reaction kinetics can be extended to other metal-air batteries for addressing the charging overpotential issue.

\section{Discussion}

In conclusion, we have successfully incorporated solar energy capturing into the charging process of a rechargeable zinc-air battery which integrates the semiconducting photoelectrode as air electrode. Under sunlight illumination, the photoelectrode undergoes photoexcitation and generates holes and electrons. The holes transfer to the photoelectrode surface to facilitate OER process, thus reducing the charging voltage. The proposed sunlight-promoted charging mechanism has been demonstrated using two typical photoelectrodes (i.e., $\mathrm{BiVO}_{4}$ and $\mathrm{a}$ $\mathrm{Fe}_{2} \mathrm{O}_{3}$ ) with different band structures. $\mathrm{BiVO}_{4}$-based zinc-air battery can be initially charged with an extremely low voltage of $\sim 1.20 \mathrm{~V}$ corresponding to $\sim 0.76 \mathrm{~V}$ reduction compared to that in dark. However, it increases quickly due to severe photocorrosion of $\mathrm{BiVO}_{4}$. In contrast, $a-\mathrm{Fe}_{2} \mathrm{O}_{3}$ exhibits promising potential as stable and efficient air photoelectrode with a low charge potential of $\sim 1.43 \mathrm{~V}$ and high cycling stability during 50 $\mathrm{h}$ discharge-charge test. It is also interesting to note that the difference in the actual charge potential $(\sim 0.23 \mathrm{~V})$ of sunlightpromoted zinc-air batteries based on two different photoelectrodes matches well with the predicted theoretical value difference $(0.20 \mathrm{~V})$. This work demonstrates that the introduction of photoelectrode with more negative $\mathrm{CB}$ and appropriate $\mathrm{VB}$ positions as well as high photoelectrochemical stability is promising for the development of zinc-air batteries with high energy efficiency. 


\section{Methods}

Electrode preparation. The porous $\mathrm{BiVO}_{4}$ photoelectrode was synthesized through electrodeposition of BiOI film on fluorine-doped tin oxide (FTO) substrate followed by thermal conversion to the porous $\mathrm{BiVO}_{4}$ film ${ }^{20}$. Briefly, $0.4 \mathrm{M} \mathrm{KI}$ solution was prepared by dissolving $20 \mathrm{mmol}$ potassium iodide (KI, $\geq 99 \%$, SigmaAldrich) into $50 \mathrm{ml}$ deionized water and adjust its $\mathrm{pH}$ to 1.7 by nitric acid $\left(\mathrm{HNO}_{3}\right.$, 65-68\%, Sinopharm Chemical Reagent Beijing Co., Ltd, China). Then, $2 \mathrm{mmol}$ bismuth(Ш) nitrate pentahydrate $\left(\mathrm{Bi}\left(\mathrm{NO}_{3}\right)_{3} \cdot 5 \mathrm{H}_{2} \mathrm{O}, \geq 99.99 \%\right.$, Sigma-Aldrich) was added into the solution and stirred by $15 \mathrm{~min}$. Afterwards, this solution was mixed with $20 \mathrm{ml}$ of absolute ethanol containing $0.4 \mathrm{M}$ p-benzoquinone ( $\geq 98 \%$, SigmaAldrich), and was vigorously stirred for $30 \mathrm{~min}$ resulting in a dark transparent black solution with a $\mathrm{pH}$ of 2.6. A typical three-electrode system was carried out for the electrodeposition, with the prepared solution as electrolyte, a FTO substrate as the working electrode (WE), a platinum foil as the counter electrode (CE) and the saturated $\mathrm{Ag} / \mathrm{AgCl}$ as the reference electrode. After potentiostatically cathodic deposition at an optimized condition of $-0.1 \mathrm{~V}$ vs. $\mathrm{Ag} / \mathrm{AgCl}$ for $5 \mathrm{~min}$, a uniform $\mathrm{BiOI}$ film was deposited on the FTO substrate followed by rinsing with deionized water and drying in ambient air. $\mathrm{BiVO}_{4}$ electrodes were prepared by dropping $0.2 \mathrm{ml}$ of a dimethyl sulfoxide (DMSO, $\geq 99.7 \%$, Sigma-Aldrich) solution containing $0.2 \mathrm{M}$ vanadyl acetylacetonate ( $\mathrm{VO}(\mathrm{acac})_{2}, 99.98 \%$, Sigma-Aldrich) onto the formed BiOI layer, followed by annealing in a muffle furnace at $450{ }^{\circ} \mathrm{C}$ (ramping rate $2{ }^{\circ} \mathrm{C} \min ^{-1}$ ) for $2 \mathrm{~h}$. To remove excess $\mathrm{V}_{2} \mathrm{O}_{5}$, the obtained $\mathrm{BiVO}_{4}$ electrodes were soaked in $1 \mathrm{M}$ potassium hydroxide $(\mathrm{KOH}, \geq 85 \%$, Sinopharm Chemical Reagent Beijing Co., Ltd, China) after cooling to room temperature. Finally, the electrodes were rinsed with deionized water $(18.2 \mathrm{M} \Omega \mathrm{cm}$, Millipore) and dried in ambient air to obtain pure $\mathrm{BiVO}_{4}$

$\alpha-\mathrm{Fe}_{2} \mathrm{O}_{3}$ photoelectrode with one dimensional nanorod arrays on the FTO substrate was prepared by a hydrothermal method and two-step annealing. Typically, a cleaned FTO glass was immersed in a Teflon-lined stainless steel autoclave containing aqueous solution of $0.15 \mathrm{M}$ ferric chloride $\left(\mathrm{FeCl}_{3}, 99.99 \%\right.$, Sigma-Aldrich) and $1 \mathrm{M}$ sodium nitrate $\left(\mathrm{NaNO}_{3}, \geq 99 \%\right.$, Sigma-Aldrich) at $\mathrm{pH} 1.25$ adjusted by hydrochloric acid $(\mathrm{HCl}, \geq 37 \%$, Sinopharm Chemical Reagent Beijing Co., Ltd, China). The hydrothermal reaction was conducted at $95^{\circ} \mathrm{C}$ for $6 \mathrm{~h}$ and naturally cooled down to room temperature. The obtained products were cleaned with deionized water and subsequently sintered in air at $550^{\circ} \mathrm{C}$ for $2 \mathrm{~h}$ to form $\mathrm{Fe}_{2} \mathrm{O}_{3}$ nanorod arrays. Afterwards, the formed $\mathrm{Fe}_{2} \mathrm{O}_{3}$ product was further annealed at $800{ }^{\circ} \mathrm{C}$ for $10 \mathrm{~min}$ for facilitating the doping of $\mathrm{Sn}$ from the FTO into $\mathrm{Fe}_{2} \mathrm{O}_{3}$ to increase the donor density in the electrode.

Characterization. The crystal structures of the obtained samples were determined by XRD (Bruker D8, Bruker Corp, USA) with $\mathrm{Cu} \mathrm{K} \mathrm{\alpha}_{\alpha}$ radiation and operating in a $2 \theta$ range of $20-80^{\circ}$ at a scan rate of $5^{\circ} \min ^{-1}$. The surface morphology of the samples was characterized by field-emission SEM (Hitachi S-4800, Japan) and TEM (JEOL $2100 \mathrm{~F}$, Japan). The Optical absorption measurements of as-prepared samples were performed using a spectrophotometer (Hitachi U-3010, Hitachi, Japan). VB analysis was carried out by XPS (Kratos Axis Ultra DLD, Kratos Analytical Ltd., UK). UPS was measured with a monochromatic He I light source $(21.2 \mathrm{eV})$ and a VG Scienta R4000 analyzer (VG Scienta Ltd., UK). A sample bias of $-5 \mathrm{~V}$ was applied to observe the secondary electron cutoff. The work function can be determined by the secondary electron cutoff at the high kinetic energy region.

Photoelectrochemical measurements. The photoelectrochemical and electrochemical performances of the photoelectrode were measured with potentiostat (Ivium Stat, Ivium Technologies, Netherlands) in a three-electrode configuration using $\mathrm{BiVO}_{4}$ or $\alpha-\mathrm{Fe}_{2} \mathrm{O}_{3}$ as the working electrode, saturated calomel electrode (SCE) as reference electrode, graphite rod as counter electrode and $1 \mathrm{M} \mathrm{KOH}$ with $\mathrm{pH}$ of 13.6 as electrolyte. In order to ensure the dark environment, the quartz electrolytic cell is wrapped in tin foil. Simulated solar illumination was provided by a $500 \mathrm{~W}$ Xe lamp equipped with an AM 1.5 G filter (CEL-S500, Beijing China Education Au-light Co. Ltd., China) and the incident photo intensity was calibrated to $100 \mathrm{~mW} \mathrm{~cm}^{-2}$ by a solar power meter. Liner sweep voltammetry (LSV) was carried out in $\mathrm{O}_{2}$-saturated electrolyte with scanning rate of $20 \mathrm{mV} \mathrm{s}^{-1}$ in dark and under simulated solar illumination, respectively. Potentials were calibrated to a RHE using the Nernst equation:

$$
\begin{gathered}
E(\text { versus } \mathrm{RHE})=E(\text { versus SCE })+E_{\mathrm{SCE}}(\text { reference })+0.0591 \mathrm{~V} \times \mathrm{pH} \\
\left(E_{\mathrm{SCE}}(\text { reference })=0.244 \mathrm{~V} \text { versus NHE at } 25^{\circ} \mathrm{C}\right)
\end{gathered}
$$

The photocurrent stability tests were conducted under continuous illumination at $1.23 \mathrm{~V}$ vs. RHE. Electrochemical impedance spectroscopy (EIS) measurements were performed in a three-electrode configuration using the electrochemical station with bias of $1.23 \mathrm{~V}$ vs. RHE in the dark and under illumination (AM $1.5 \mathrm{G} ; 100$ $\mathrm{mW} \mathrm{cm}{ }^{-2}$ ), respectively. Mott-Schottky measurements were carried out in $1 \mathrm{M}$ $\mathrm{KOH}$ aqueous solution at a frequency of $1 \mathrm{kHz}$ with a scan rate of $10 \mathrm{mV} \mathrm{s}^{-1}$ in the dark. The donor densities were calculated with the following equation:

$$
N_{\mathrm{D}}=\left(2 / e \varepsilon \varepsilon_{0}\right)\left[\mathrm{d}\left(1 / C^{2}\right) / \mathrm{d} V\right]^{-1}
$$

where $N_{\mathrm{d}}$ is the donor concentration, $e$ the electron charge $\left(1.60 \times 10^{-19}\right), C$ the electron charge, $\varepsilon$ the dielectric constant $\left(\varepsilon=68\right.$ for $\mathrm{BiVO}_{4}{ }^{38}$, and $\varepsilon=80$ for $\alpha$ $\mathrm{Fe}_{2} \mathrm{O}_{3}{ }^{39}, \varepsilon_{o}$ the vacuum permittivity $\left(8.85 \times 10^{-14} \mathrm{~F} \mathrm{~cm}^{-1}\right), C$ the capacitance of the space charge region, and $V$ is the electrode applied potential.
Sunlight-promoted zinc-air batteries assembly. The zinc-air battery tests were performed by the home-made liquid zinc-air battery which was assembled using a polished $\mathrm{Zn}$ foil ( $0.25 \mathrm{~mm}$ thickness) as the metal electrode and the semiconductor photoelectrode (i.e., $\mathrm{BiVO}_{4}$ or $\alpha-\mathrm{Fe}_{2} \mathrm{O}_{3}$ ) as the air electrode. The electrolyte used was $1 \mathrm{M} \mathrm{KOH}$ with $0.03 \mathrm{M}$ zinc acetate $\left(\mathrm{Zn}\left(\mathrm{CH}_{3} \mathrm{COO}\right)_{2}, 99.99 \%\right.$, Sigma-Aldrich) (dissolved in $\mathrm{KOH}$ to form zincate, $\mathrm{Zn}(\mathrm{OH})_{4}^{2-}$ ) to ensure reversible $\mathrm{Zn}$ electrochemical reactions at the $\mathrm{Zn}$ electrode. For comparison, the performance of sunlight-promoted rechargeable zinc-air batteries was tested under the same conditions as traditional zinc-air batteries except the illumination on the photoelectrode. The galvanostatic discharge-charge cycling tests $(20 \mathrm{~min}$ discharge followed by $20 \mathrm{~min}$ charge) were performed by Land-CT2001A battery-testing system (Wuhan LAND Electronic Co., Ltd, China) in the dark and under illumination, respectively. The specific capacity $\left(\mathrm{mAh} \mathrm{g}^{-1}\right)$ and the energy density $\left(\mathrm{mWh}^{-1}\right)$ based on the weight of consumed $\mathrm{Zn}$ are calculated according to Eqs. 15 and 16:

$$
\text { Specific capacity }=\frac{\text { Discharge current } \times \text { Service hours }}{\text { the weight of consumed } \mathrm{Zn}}
$$

$$
\text { Energy density }=\frac{\text { Discharge current } \times \text { Service hours } \times \text { Average discharge voltage }}{\text { the weight of consumed Zn }}
$$

\section{Data availability}

The data that support the findings of this study are available from the corresponding author upon reasonable request.

Received: 11 May 2019; Accepted: 21 September 2019; Published online: 18 October 2019

\section{References}

1. Chen, P., Li, G. R., Li, T. T. \& Gao, X. P. Solar-Driven Rechargeable Lithium-Sulfur Battery. Adv. Sci. 6, 1900620 (2019).

2. Cao, R., Lee, J. S., Liu, M. \& Cho, J. Recent progress in non-precious catalysts for metal-air batteries. Adv. Energy Mater. 2, 816-829 (2012).

3. Liu, Y. et al. Lowering the charge voltage of $\mathrm{Li}-\mathrm{O}_{2}$ batteries via an unmediated photoelectrochemical oxidation approach. J. Mater. Chem. A 4, 12411-12415 (2016).

4. Liu, Y. et al. Reducing the charging voltage of a $\mathrm{Li}-\mathrm{O}_{2}$ battery to $1.9 \mathrm{~V}$ by incorporating a photocatalyst. Energy Environ. Sci. 8, 2664-2667 (2015).

5. Paolella, A. et al. Light-assisted delithiation of lithium iron phosphate nanocrystals towards photo-rechargeable lithium ion batteries. Nat. Commun. 8, 14643-14652 (2017).

6. Lei, B., Li, G. R., Chen, P. \& Gao, X. P. A quasi-solid-state solar rechargeable battery with polyethylene oxide gel electrolyte. ACS Appl. Energy Mater. 2, 1000-1005 (2019).

7. Wang, Z. et al. Lithium photo-intercalation of CdS-sensitized $\mathrm{WO}_{3}$ anode for energy storage and photoelectrochromic applications. ChemSusChem 12, 2220-2230 (2019).

8. Li, Y. et al. Advanced zinc-air batteries based on high-performance hybrid electrocatalysts. Nat. Commun. 4, 1805-1811 (2013).

9. Li, Y. \& Dai, H. Recent advances in zinc-air batteries. Chem. Soc. Rev. 43 5257-5275 (2014)

10. Cheng, F. \& Chen, J. Metal-air batteries: from oxygen reduction electrochemistry to cathode catalysts. Chem. Soc. Rev. 41, 2172-2192 (2012).

11. Sapkota, P. \& Kim, H. Zinc-air fuel cell, a potential candidate for alternative energy. J. Ind. Eng. Chem. 15, 445-450 (2009).

12. Tan, P. et al. Flexible $\mathrm{Zn}$ - and Li-air batteries: recent advances, challenges, and future perspectives. Energy Environ. Sci. 10, 2056-2080 (2017).

13. Lee, D. U. et al. Advanced extremely durable $3 \mathrm{D}$ bifunctional air electrodes for rechargeable zinc-air batteries. Adv. Energy Mater. 4, 1301389 (2014).

14. Jung, J. I. et al. Optimizing nanoparticle perovskite for bifunctional oxygen electrocatalysis. Energy Environ. Sci. 9, 176-183 (2016).

15. Koper, M. T. M. Thermodynamic theory of multi-electron transfer reactions: implications for electrocatalysis. J. Electroanal. Chem. 660, 254-260 (2011).

16. Li, Y. et al. Recent advances in flexible zinc-based rechargeable batteries. $A d v$. Energy Mater. 9, 1802605 (2019).

17. Yeo, B. S. \& Bell, A. T. Enhanced activity of gold-supported cobalt oxide for the electrochemical evolution of oxygen. J. Am. Chem. Soc. 133, 5587-5593 (2011).

18. Sun, Y. T. et al. Recent advances and challenges in divalent and multivalent metal electrodes for metal-air batteries. J. Mater. Chem. A 7, 18183-18208 (2019).

19. Lee, J.-S. et al. Metal-air batteries with high energy density: Li-air versus Zn-air. Adv. Energy Mater. 1, 34-50 (2011). 
20. Kim, T. W. \& Choi, K. S. Nanoporous $\mathrm{BiVO}_{4}$ photoanodes with dual-layer oxygen evolution catalysts for solar water splitting. Science 343, 990-994 (2014).

21. $\mathrm{Li}, \mathrm{C}$. et al. Surviving high-temperature calcination: $\mathrm{ZrO}_{2}$-induced hematite nanotubes for photoelectrochemical water oxidation. Angew. Chem. Int. Ed. 56, 4150-4155 (2017).

22. Kay, Andreas, Cesar, Ilkay \& Grätzel, M. New benchmark for water photooxidation by nanostructured $\alpha-\mathrm{Fe}_{2} \mathrm{O}_{3}$ films. J. Am. Chem. Soc. 128 15714-15721 (2006).

23. Pilli, S. K. et al. Cobalt-phosphate (Co-Pi) catalyst modified Mo-doped $\mathrm{BiVO}_{4}$ photoelectrodes for solar water oxidation. Energy Environ. Sci. 4, 5028-5034 (2011).

24. Tang, P. et al. Enhanced photoelectrochemical water splitting of hematite multilayer nanowire photoanodes by tuning the surface state via bottom-up interfacial engineering. Energy Environ. Sci. 10, 2124-2136 (2017).

25. He, L. et al. Enhanced visible activities of $\alpha-\mathrm{Fe}_{2} \mathrm{O}_{3}$ by coupling N-doped graphene and mechanism insight. ACS Catal. 4, 990-998 (2014).

26. Wang, G. et al. Facile synthesis of highly photoactive $\alpha-\mathrm{Fe}_{2} \mathrm{O}_{3}$-based films for water oxidation. Nano Lett. 11, 3503-3509 (2011).

27. Phuan, Y. W. et al. In situ Ni-doping during cathodic electrodeposition of hematite for excellent photoelectrochemical performance of nanostructured nickel oxide-hematite p-n junction photoanode. Appl. Surf. Sci. 392, 144-152 (2017).

28. Kennedy, JohnH., Karl, W. \& Frese, J. Flatband potentials and donor densities of polycrystalline $\alpha-\mathrm{Fe}_{2} \mathrm{O}_{3}$ determined from Mott-Schottky plots. $J$. Electrochem. Soc. 125, 723-725 (1978).

29. Schoonman, J., Vos, K. \& Blasse, G. Donor densities in $\mathrm{TiO}_{2}$ photoelectrodes. J. Electrochem. Soc. 128, 1154-1157 (1981).

30. Cronemeyer, D. C. Infrared absorption of reduced rutile $\mathrm{TiO}_{2}$ single crystals. Phys. Rev. 113, 1222-1226 (1959).

31. Wang, G. et al. Hydrogen-treated $\mathrm{TiO}_{2}$ nanowire arrays for photoelectrochemical water splitting. Nano Lett. 11, 3026-3033 (2011).

32. Bak, T., Nowotny, J., Rekas, M. \& Sorrell, C. C. Photoelectrochemical hydrogen generation from water using solar energy. Materials-related aspects. Int. J. Hydrog. Energy 27, 991-1022 (2002)

33. Wang, G. et al. Chemically modified nanostructures for photoelectrochemical water splitting. J. Photochem. Photobiol. C. 19, 35-51 (2014).

34. Gleim, T. et al. Formation of the $\mathrm{ZnSe} /(\mathrm{Te} /) \mathrm{GaAs}(100)$ heterojunction. Surf. Sci. 531, 77-85 (2003)

35. Cooper, J. K. et al. Electronic structure of monoclinic $\mathrm{BiVO}_{4}$. Chem. Mater. 26, 5365-5373 (2014)

36. Matsumoto, Y., Yoshikawa, T. \& Sato, E.-i Dependence of the band bending of the oxide semiconductors on pH. J. Electrochem. Soc. 136, 1389-1391 (1989).

37. Xu, Y. \& Schoonen, M. A. A. The absolute energy positions of conduction and valence bands of selected semiconducting minerals. Am. Mineral. 85, 543-556 (2000).

38. Wee, S. H., Kim, D. W. \& Yoo, S. I. Microwave dielectric properties of low-fired $\mathrm{ZnNb}_{2} \mathrm{O}_{6}$ ceramics with $\mathrm{BiVO}_{4}$ addition. J. Am. Ceram. Soc. 87, 871-874 (2008).

39. Benko, F. A., Longo, J. \& Koffyberg, F. P. A comparison of photochemical properties of amorphous and polycrystalline. J. Electrochem. Soc. 132, 609-613 (1985).

\section{Acknowledgements}

This work was supported by the National Science Foundation for Excellent Young Scholar (No. 51722403), and the National Natural Science Foundation of China (No. 51771134), National Youth Talent Support Program, National Natural Science Foundation of China and Guangdong Province (No. U1601216), and Tianjin Natural Science Foundation for Distinguished Young Scholar (No. 18JCJQJC46500).

\section{Author contributions}

C.Z. designed the experiments. X.L. and Y.Y. performed the experiments and analyzed the results. X.L. and X.H. performed the calculation study. X.C. performed SEM measurements. J.L. performed XRD measurements. X.L. and B.L. aggregated the figures. X.L., Y.Y. and C.Z. wrote the draft. C.Z. and Y.Y. revised the manuscript. J.D. and Y.D. checked the calculations. W.H. and C.Z. supervised the overall research. All authors discussed the results and commented on the manuscript.

\section{Competing interests}

The authors declare no competing interests.

\section{Additional information}

Supplementary information is available for this paper at https://doi.org/10.1038/s41467 019-12627-2.

Correspondence and requests for materials should be addressed to C.Z. or W.H.

Peer review information Nature Communications thanks Karim Zaghib and the other, anonymous, reviewer(s) for their contribution to the peer review of this work.

Reprints and permission information is available at http://www.nature.com/reprints

Publisher's note Springer Nature remains neutral with regard to jurisdictional claims in published maps and institutional affiliations.

Open Access This article is licensed under a Creative Commons Attribution 4.0 International License, which permits use, sharing, adaptation, distribution and reproduction in any medium or format, as long as you give appropriate credit to the original author(s) and the source, provide a link to the Creative Commons license, and indicate if changes were made. The images or other third party material in this article are included in the article's Creative Commons license, unless indicated otherwise in a credit line to the material. If material is not included in the article's Creative Commons license and your intended use is not permitted by statutory regulation or exceeds the permitted use, you will need to obtain permission directly from the copyright holder. To view a copy of this license, visit http://creativecommons.org/ licenses/by/4.0/.

(C) The Author(s) 2019 